\title{
Multifocal Micronodular Pneumocyte Hyperplasia in a Man with Tuberous Sclerosis
}

\author{
Yoshihiro KoBASHI, Kouichiro YOSHIDA, Naoyuki MiYASHITA, \\ Yoshihito NIKI, Toshiharu MATSUSHIMA and Tutomu IREI*
}

\begin{abstract}
We report a peculiar case of multifocal micronodular pneumocyte hyperplasia (MMPH) occurring in a 43year-old man with tuberous sclerosis. Computed tomography of the chest demonstrated multiple micronodules, measuring up to $5 \mathrm{~mm}$ in size, present bilaterally in the lung fields, with no cystic change. Histologically, a proliferation of type II pneumocytes without the typical nulclear atypia lined the thickened alveolar septa in an adenomatoid pattern. Proliferation of immature smooth muscle cells suggestive of LAM was not observed. The characteristic findings of the positive immunohistochemical stains for cytokeratin and surfactant apoprotein A and $B$, and negative stains for HMB-45, alpha-1 smooth muscle actin, desmin, p53 and carcinoembryonic antigen confirmed the presence of alveolar lining cells in each MMPH lesion. Since the MMPH was observed in a male and did not appear to possess malignant potential, the MMPH appears to be a hamartomatous proliferation occurring in a male with tuberous sclerosis that is separate from lymphangiomyomatosis (LAM) which is related to estrogen and progesterone receptors.

(Internal Medicine 44: 462-466, 2005)
\end{abstract}

Key words: multifocal micronodular pneumocyte hyperplasia (MMPH), tuberous sclerosis, lymphangioleiomatosis (LAM)

\section{Introduction}

Tuberous sclerosis is an autosomal dominant disorder characterized by the presence of hemartias and the growth of hamartomas in one or more organs. Although the central nervous system, skin, kidney, heart, retina and lung are the most commonly involved, nearly any organ in the body can be affected (1). Tuberous sclerosis has a relatively high penetrate $(90-95 \%)$, and the prevalence has been estimated at $1: 30,000$ individuals under the age of 65 years and $1: 15,000$ under the age of five years (2). According to another study, the prevalence was $1: 10,000$ and the birth incidence $1: 5,800$ (3). Tuberous sclerosis does not occur predominantly in any gender, race or geographical location. With respect to pulmonary involvement, lymphangioleiomyomatosis (LAM) is found in $1 \%$ of cases (4), while multifocal micronodular pneumocyte hyperplasia (MMPH) is extremely rare (5). The majority of tuberous sclerosis patients with MMPH are women of premenopausal age who also have LAM. However, there is a particularly interesting tuberous sclerosis case with MMPH occurring in a male mentioned in a previous report $(6,7)$. Here, we describe a male with tuberous sclerosis and pulmonary involvement manifested by MMPH without LAM clinicopathologically.

\section{Case Report}

A 43-year-old man had been diagnosed as having tuberous sclerosis associated with angiofibroma of the face and bilateral renal angiolipoma. He was admitted to our hospital because of abnormal findings on computed tomography (CT) of the chest done as a systemic screening examination for tuberous sclerosis. The patient had no family history of tuberous sclerosis, no respiratory symptoms and did not smoke. He had been diagnosed as having epilepsy five years previously and manifestation of his tuberous sclerosis. However, he had mental retardation. Physical examination including a neurological examination revealed no abnormalities. Laboratory data on admission are shown in Table1. There were no abnormal laboratory tumor marker findings. Chest $\mathrm{X}$-ray on admission showed almost normal findings. No emphysematous changes, interstitial fibrosis, increased lung volume, or pleural effusions were found. Chest CT revealed

From the Division of Respiratory Diseases, the Department of Medicine, and *the Department of Pathology, Kawasaki Medical School, Kurashiki Received for publication April 22, 2004; Accepted for publication November 15, 2004

Reprint requests should be addressed to Dr. Yoshihiro Kobashi, the Division of Respiratory Diseases, Department of Medicine, Kawasaki Medical School, 577 Matsushima, Kurashiki 701-0192 
Multifocal Micronodular Pneumocyte Hyperplasia (MMPH)

Table 1. Laboratory Data on Admission

\begin{tabular}{|c|c|c|c|}
\hline \multicolumn{2}{|c|}{ Peripheral blood } & \multicolumn{2}{|l|}{ Serology } \\
\hline $\mathrm{RBC}$ & $438 \times 10^{4} / \mu 1$ & IgG & $1,400 \mathrm{mg} / \mathrm{dl}$ \\
\hline $\mathrm{Hb}$ & $13.2 \mathrm{~g} / \mathrm{dl}$ & $\operatorname{IgA}$ & $186 \mathrm{mg} / \mathrm{dl}$ \\
\hline $\mathrm{Ht}$ & $40.3 \%$ & IgM & $165 \mathrm{mg} / \mathrm{dl}$ \\
\hline WBC & $5,080 / \mu \mathrm{l}$ & IgD & $1.1 \mathrm{mg} / \mathrm{dl}$ \\
\hline Seg & $70 \%$ & $\operatorname{IgE}$ & $19 \mathrm{I} \mathrm{U} / \mathrm{ml}$ \\
\hline Mono & $1 \%$ & CEA & $<1.0 \mathrm{ng} / \mathrm{ml}$ \\
\hline Lym & $29 \%$ & CA19-9 & $<5.0 \mathrm{U} / \mathrm{ml}$ \\
\hline Plt & $28.6 \times 10^{4} / \mu 1$ & $\mathrm{SCC}$ & $<0.5 \mathrm{ng} / \mathrm{ml}$ \\
\hline ESR & $20 \mathrm{~mm} / \mathrm{h}$ & SLX & $23.8 \mathrm{U} / \mathrm{ml}$ \\
\hline \multicolumn{2}{|c|}{ Blood chemistry } & TPA & $11 \mathrm{U} / l$ \\
\hline TP & $7.9 \mathrm{~g} / \mathrm{dl}$ & NSE & $6.8 \mathrm{ng} / \mathrm{ml}$ \\
\hline BS & $82 \mathrm{mg} / \mathrm{dl}$ & ProGRP & $18.3 \mathrm{pg} / \mathrm{ml}$ \\
\hline Bil (T) & $0.5 \mathrm{mg} / \mathrm{dl}$ & CYFRA & $<1.0 \mathrm{ng} / \mathrm{ml}$ \\
\hline ALP & $249 \mathrm{IU} / l$ & SP-D & $77.2 \mathrm{ng} / \mathrm{ml}$ \\
\hline Cho & $216 \mathrm{mg} / \mathrm{dl}$ & KL-6 & $188 \mathrm{U} / \mathrm{ml}$ \\
\hline$\gamma$-GTP & $18 \mathrm{IU} / \mathrm{l}$ & Canditec & $(-)$ \\
\hline LDH & $149 \mathrm{IU} / l$ & Cryptococcus antigen & $(-)$ \\
\hline $\mathrm{Alb}$ & $4.8 \mathrm{~g} / \mathrm{dl}$ & Cryptococcus antibody & $(-)$ \\
\hline Glb & $3.1 \mathrm{~g} / \mathrm{dl}$ & Aspergillus antigen & $(-)$ \\
\hline $\mathrm{ChE}$ & $385 \mathrm{IU} / l$ & Aspergillus antibody & $(-)$ \\
\hline GPT & $20 \mathrm{IU} / l$ & $\beta$-D-glucan & $<6.0 \mathrm{pg} / \mathrm{ml}$ \\
\hline GOT & $15 \mathrm{IU} / \mathrm{l}$ & ANA & $(-)$ \\
\hline Crn & $0.84 \mathrm{mg} / \mathrm{dl}$ & $\mathrm{CH}_{50}$ & $39.9 \mathrm{U} / \mathrm{ml}$ \\
\hline BUN & $22 \mathrm{mg} / \mathrm{dl}$ & $\beta_{2}$-microgloburin & $1.9 \mu \mathrm{g} / \mathrm{ml}$ \\
\hline UA & $5.4 \mathrm{mg} / \mathrm{dl}$ & Ccr & $97.0 \mathrm{ml} / \mathrm{min}$ \\
\hline Amy & $67 \mathrm{IU} / l$ & \multicolumn{2}{|l|}{ Pulmonary function test } \\
\hline CRP & $0.10 \mathrm{mg} / \mathrm{dl}$ & $\% \mathrm{VC}(\mathrm{VC})$ & $109.6 \%(4.42 l)$ \\
\hline $\mathrm{Na}$ & $143 \mathrm{mEq} / \mathrm{l}$ & $\mathrm{FEV}_{1.0} \%\left(\mathrm{FEV}_{1.0}\right)$ & $82.5 \%(3.72 l)$ \\
\hline $\mathrm{K}$ & $4.5 \mathrm{mEq} / \mathrm{l}$ & $\%$ DLco & $102.0 \%$ \\
\hline $\mathrm{Cl}$ & $103 \mathrm{mEq} / \mathrm{l}$ & PPD & $0 \times 0$ \\
\hline $\mathrm{P}$ & $4.4 \mathrm{mg} / \mathrm{dl}$ & & $16 \times 10$ \\
\hline $\mathrm{Ca}$ & $9.8 \mathrm{mg} / \mathrm{dl}$ & Urine & \\
\hline \multirow[t]{4}{*}{$\mathrm{Mg}$} & $2.2 \mathrm{mg} / \mathrm{dl}$ & Protein & $(-)$ \\
\hline & & Sugar & $(-)$ \\
\hline & & Blood & $(-)$ \\
\hline & & Stool Blood & $(-)$ \\
\hline
\end{tabular}

multiple micronodular shadows smaller than $5 \mathrm{~mm}$ in diameter in the lung fields bilaterally (Fig. 1). However, cystic changes suggestive of LAM were absent. To obtain a histopathological diagnosis, we performed a thoracoscopic procedure and specimens were resected from the right upper lobe of the lung. Magnetic resonance imaging (MRI) of the head revealed a subependymal tumor extending bilaterally into the lateral brain spaces. Screening abdominal echogram revealed several tumors corresponding to angiomyolipomas encroaching bilaterally into the kidneys.

Thoracoscopy showed multiple small white nodules up to $5 \mathrm{~mm}$ in diameter, which were scattered in the subpleural parenchyma in each lobe of the right lung. The lung surface showed no cystic lesions suggestive of LAM. A resected specimens showed four white firm nodules of varying sizes ranging from $1 \mathrm{~mm}$ to $3 \mathrm{~mm}$ in diameter, scattered in the lung parenchyma.

Histopathologically, these several nodules had a compara- tively clear margin, the largest nodule measuring $3 \mathrm{~mm}$ in diameter (Fig. 2A), and were composed of a proliferation of type II pneumocytes. The center of the small nodules showed papillary or trabecular growth pattern. The stroma of these nodules showed a fibrous thickening of the alveolar septa of the elastosis. The type II pneumocytes were enlarged and varies in shape from flattened to cuboidal or round, sometimes with clear nucleolus, but demonstrated no intranulceolar inclusion bodies. They lacked marked nuclear atypia or mitotic figures. A mild infiltration of lymphocytes in the thickened alveolar lumens and aggregations of macrophages in the alveolar lumens were also observed (Fig. 2B). A proliferation of immature smooth muscle cells suggestive of LAM was not observed, in any area including the thickened alveolar septum or the area around the pulmonary arteries and bronchioles. Further, emphysematous lesions as seen in cases of LAM were not observed.

Immunohistochemical investigations revealed that all pro- 


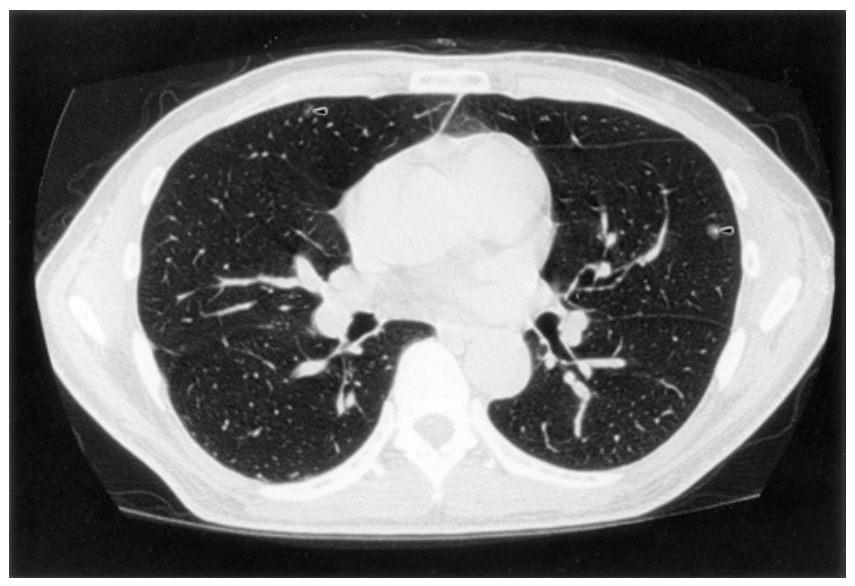

A

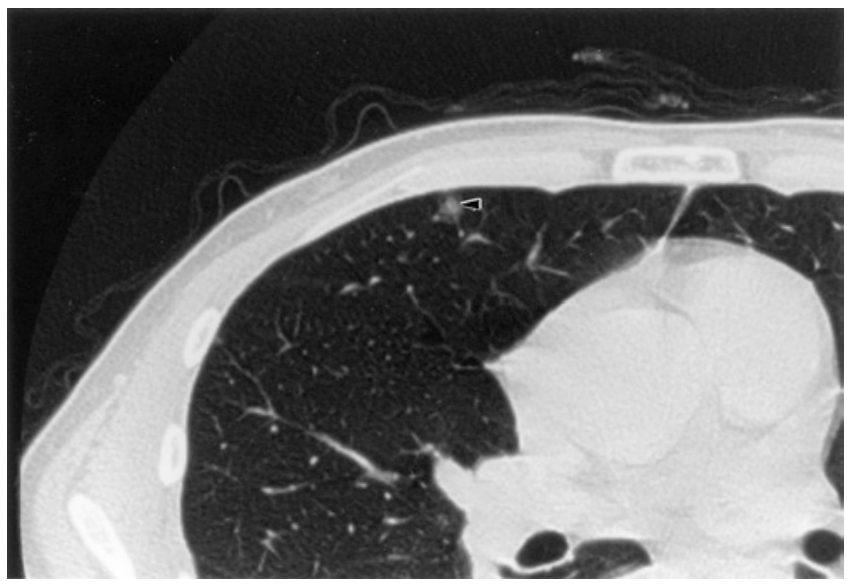

B

Figure 1. Chest CT on admission showing multiple micronodules (arrowhead) in the lung fields bilaterally (A) and the magnification of micronodule in the segment 3 of the right lung $(B)$.

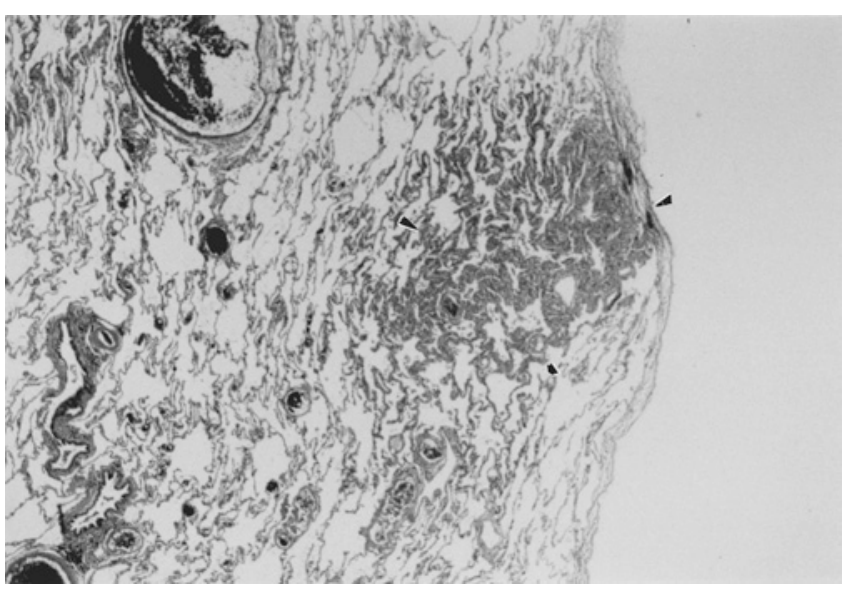

A

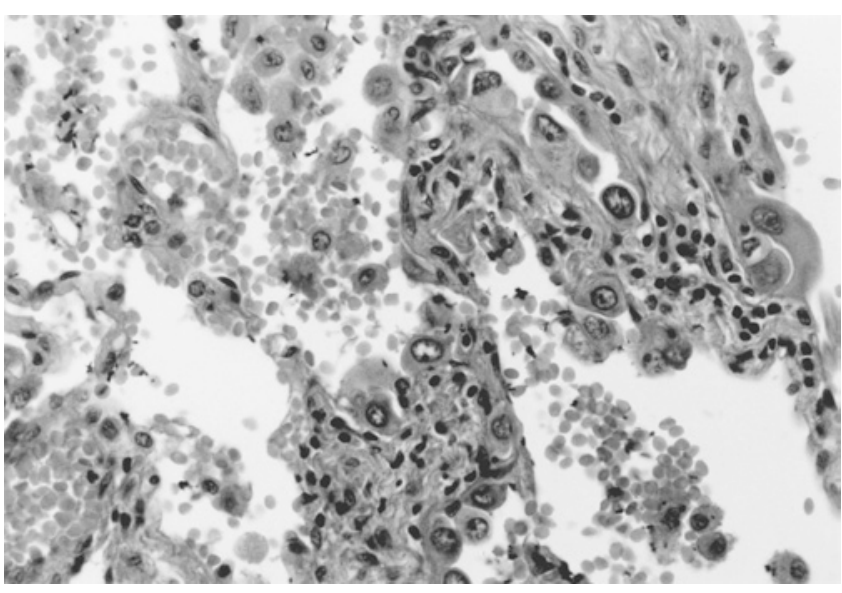

B

Figure 2. Low-power view showing micronodule (arrowhead) which had a comparatively clear margin and were composed of a proliferation of type II pneumocytes. The center of the micronodule showing papillary or trabecular growth pattern (A) (HE staining, $\times 10$ ). High-power view showing the fibrous thickening of the alveolar septa of the elastosis. The type II pneumocytes were enlarged and varied in shape from flattened to cuboidal or round. A mild infiltration of lymphocytes in the thickened alveolar septa and aggregations of macrophages in the alveolar lumens (B) (HE staining, ×200).

liferating alveolar epithelial cells were intensely stained by cytokeratin antibodies (Fig. 3). In addition, these cells were positive for monoclonal antibodies of surfactant apoprotein A and B. However, proliferating epithelial cells and smooth muscle cells in the thickened alveolar septa were negative for CEA, p53, desmin, alpha-1 smooth muscle actin and HMB45. They were also negative for anti-estrogen and antiprogesterone receptor monoclonal hormonal antibodies.

\section{Discussion}

There are only a few references in the English language literature to the distinctive micronodular epithelial hyper- plastic lesion that is rarely found in the lungs of patients with tuberous sclerosis $(8-10)$. The hamartomatous nature of these peculiar epithelial proliferations has been emphasized by all of the researchers who have identified them, by the use of such as "acinar atypical adenomatoid proliferation of epithelium" (11), "multiple adenomatoid lesions" (12), "micronodular hyperplasia of type II pneumocytes" (10). Recently, based on the number and location of the lesions, as well as their apparent epithelial origin, the term multifocal micronodular pneumocyte hyperplasia (MMPH) has become commonly used (13),

From the few available reports, it would appear that MMPH occurs both in patients with $(8,9)$ and without $(10)$ 


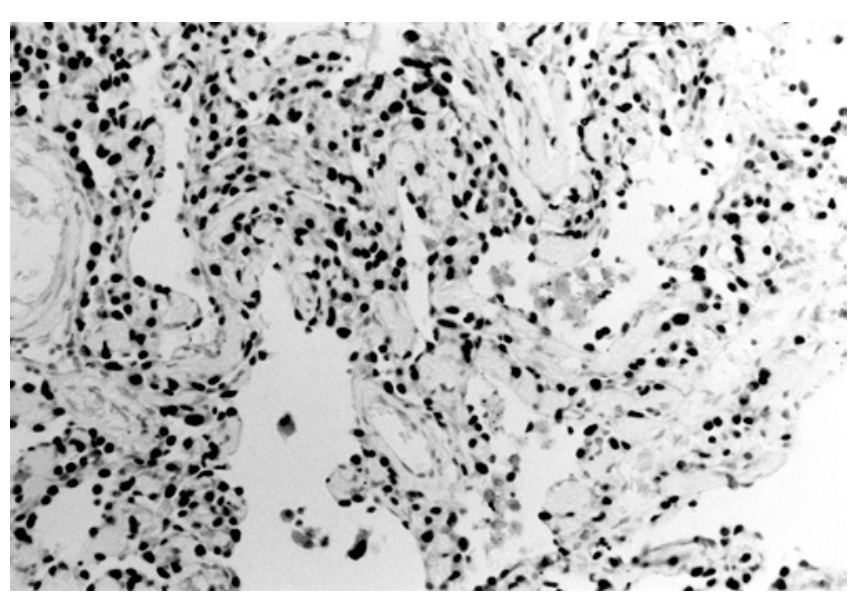

Figure 3. Proliferating alveolar epithelial cells were intensely stained by cytokeratin immunohistochemically (Immunoperoxidase, $\times 50$ ).

associated LAM. However, little attention has been focused on the true nature of these peculiar lesions. Though the study of Popper et al (10) suggested a hamartomatous proliferation of type II pneumocytes, this conclusion was based on limited morphological and ultrastructual data. However, in the present study, the positive immunohistochemical staining for cytokeratin in the proliferated cells confirmed epithelial differentiation. As well positive staining for surfactant apoprotein A and B provided additional evidence of type II pneumocyte origin (14). HMB-45 is recognized as a marker for LAM that is immunohistochemically distinct from other pulmonary smooth muscle proliferation (15). The findings in $\operatorname{LAM}(16,17)$ are different from those in MMPH. In fact, the studies so far have reported no immunoreactivity for HMB45 as well as negative results for estrogen and progesterone receptors in MMPH $(13,16-18)$. In cases with combined LAM and MMPH, the characteristic manifestation of LAM ended at the edges of the MMPH lesions (6). The negative staining for HMB-45 in the MMPH lesions indicates that the pathogenesis of the MMPH is probably separate from that of the smooth muscle cell proliferation of LAM. Histologically, the most important differential diagnosis for MMPH is atypical bronchioalveolar cell hyperplasia. It is usually found in the parenchyma adjacent to other lung carcinomas, and may represent a precursor to adenocarcinoma (19-21). In this case, there was no malignant lesion on histological finding in the specimen of VATS and proliferating epithelial cells were all negative for p53 or CEA immunohistochemically. Unlike atypical bronchioalveolar cell hyperplasia, there is no evidence that MMPH is preneoplastic.

Concerning the germline mutation analysis using leukocytes of patients, two predisposing genes have recently been found in families affected by tuberous sclerosis; approximately half of the families show linkage to TSC1 at 9q34.3, and the other half show linkage to TSC2 at 16p13.3 (22). Murayama et al (23) mentioned that the loss of hetero- zygosity ( $\mathrm{LOH}$ ) of the TSC2 gene preliminarily was detected in a LAM lesion but not in MMPH. Unfortunately however, we could be not investigate the germline mutaion analysis for this case. It is suggested that MMPH, addition to LAM, could be another pulmonary lesion in tuberous sclerosis patients and that the detection of TSC1 or TSC2 gene could be useful for the pathogenesis of MMPH and LAM in tuberous sclerosis patients.

In previous reports $(5,6,13,24)$, most of the tuberous sclerosis patients with pulmonary MMPH involvement were premenoposal women. Although Muir et al (6) first reported that MMPH had been observed in two men with tuberous sclerosis, and then Popper et al reported MMPH in one male case, there were no precise clinicopathological explanations given. Therefore, we have provided a clinicopathological case report of a male with tuberous sclerosis and pulmonary involvement manifested by MMPH without LAM. The present patient had other associated clinical findings including: a subependymal lesion of the brain, angiomyolipoma of kidneys bilaterally and a dermal angiofibroma, in addition to MMPH.

The clinical significance of MMPH in patients with tuberous sclerosis is unknown. It does not appear to be potentially fatal and it differs in this respect from LAM. In the present case, there were no respiratory symptoms because only MMPH lesions and no LAM lesions were present, LAM was ruled out on CT of the chest during the follow-up of this patient. In fact, multiple emphysematous areas suggestive of incipient LAM were not shown on CT of the chest. We think that the absence of estrogen and progesterone receptors ass shown by the immunohistochemical investigation suggests that there is no hormonal factor in the atypical epithelial proliferation or the smooth muscle proliferation in MMPH without LAM. Therefore, there are no available hormonal manipulations, including oophorectomy, medroxyprogesterone acetates, or tamoxifen that would be of use $(25,26)$.

Since the patient had no family history of tuberous sclerosis, the present case is a sporadic case rather than a familial case. There was no association with LAM. The MMPH in the present male case was diagnosed during a surgical procedure using video-assisted thoracoscopic surgery (VATS). It is thought that the prognosis is not poor in male tuberous sclerosis patients with MMPH. Nevertheless, a definitive diagnosis should be made, and therefore we think that a surgical procedure such as VATS is valuable in obtaining a correct diagnosis in a tuberous sclerosis patient showing multifocal micronodular lesions on $\mathrm{CT}$ of the chest. However, using genetic and immunohistochemical techniques, the histogenesis of hamartomatous lesions such as MMPH and LAM in tuberous sclerosis patients should be clarified in association with the TSC1 or TSC2 gene in the future in order to determine appropriate treatment for MMPH and LAM in tuberous sclerosis.

Acknowledgements: The authors are grateful to Dr. M. Nakata, an
Associate Professor in the Department of Thoracic Surgery, Kawasaki 


\section{KOBASHI et al}

Medical School, for his kind assistance regarding the surgical division in this study.

\section{References}

1) Castro M, Shepard CW, Gomez MR, Lie JT, Ryu JH. Pulmonary tuberous sclerosis. Chest 107: 189-195, 1995.

2) Lindor NM, Greene MH. The Mayo Familial Cancer Program, Special article: The concise handbook of family cancer syndrome. J Natl Cancer Inst 90: 1066-1067, 1998.

3) Osborne JP, Fryer A, Webb D. Epidemiology of tuberous sclerosis Ann NY Acad Sci 615: 125-127, 1991.

4) Bonetti F, Chiodera P. The lung in tuberous sclerosis. In Corrin B (ed) Pathology of the lung tumors. Churchill Livingstone, New York, 1997: 225-239.

5) Yamanaka A, Kitaichi M, Fujimoto T, Hirai T, Hori H, Konishi F. Multifocal micronodular pneumocyte hyperplasia in a postmenopausal woman with tuberous sclerosis. Virchows Arch 436: 389-392, 2000.

6) Muir TE, Leslie KO, Popper $\mathrm{H}$, et al. Micronodular pneumocyte hyperplasia. Am J Surg Pathol 22: 465-472, 1998.

7) Popper HH. Micronodular hyperplasia of type II pneumocytes (letter). Histopathology 20: 281, 1992.

8) Lie JT, Miller RD, Williams DE. Cystic disease of the lungs in tuberous sclerosis: clinicopathologic correlation, including body plethysmographic lung function tests. Mayo Clin Proc 55: 547-555, 1980.

9) Spencer H. Pathology of the lung, Ed 4. Raven Press, New York, 1985: 1043-1053.

10) Popper HH, Juettner-Smolle FM, Pongratz MG. Micronodular hyperplasia of type II pneumocytes - a new lung lesion associated with tuberous sclerosis. Histopathology 18: 347-354, 1991.

11) Corrin B, Liebow HH, Friedman PJ. Pulmonary lymphangioleiomyomatosis. Jpn J Chest Dis 37: 216-222, 1988.

12) Okamura H, Yamauchi H. Pulmonary manifestations of tuberous sclerosis: its relationship to pulmonary lymphangioleiomatosis. Jpn J Chest Dis 37: 216-222, 1988

13) Guinee D, Singh R, Azumi W, et al. Multifocal micronodular pneumocyte hyperplasia: a distinctive pulmonary manifestation of tuberous sclerosis. Mod Pathol 8: 902-906, 1995.

14) Kuroki Y, Dempo K, Akino T. Immunohistochemical study of human pulmonary surfactant apoprotein with monoclonal antibodies. Patho- logic application for hyaline membrane disease. Am J Pathol 124: 2532, 1986.

15) Bonetti F, Chiodera PL, Pea M, et al. Transbronchial biopsy in lymphangiomyomatosiss of the lung. HMB-45 for diagnosis. Am J Surg Pathol 17: 1092-1102, 1993.

16) Chuah KL, Tan PH. Multifocal micronodular pneumocyte hyperplasia, lymphangiomyomatosis and clear cell micronodules of the lung in a Chinese female patient with tuberous sclerosis. Pathology 30: 242-246, 1998.

17) Flieder DB, Trvis WD. Clear cell "sugar" tumor of the lung: association with lymphangioleiomyomatosis and multifocal micronodular pneumocyte hyperplasia in a patient with tuberous sclerosis. Am J Surg Pathol 21: 1242-1247, 1997.

18) Lantuejoul S, Ferretti G, Negoescu A, Parent B, Brambilla E. Multifocal alverolar hyperplasia associated with lymphangioleiomyomatosis in tuberous sclerosis. Histopathology 30: 570-575, 1997.

19) Weng SY, Tsuchiya E, Satoh Y, Kitagawa T, Nakagawa K, Sugano H. Multiple atypical adenomaatous hyperplasia of type II pneumocytes and bronchiolo-alveolar carcinoma. Histopathology 16: 101-107, 1990.

20) Weng SY, Tsuchiya E, Kasuga T, Sugano H. Incidence of atypical bronchioloalveolar cell hyperplasia of the lung: relation to histological subtypes of lung cancer. Virchows Arch A Patholl Anat Histopaathol 420: 463-470, 1992.

21) Nakanishi K. Alveolar epithelial hyperplasia and adenocarcinoma of the lung. Arch Pathol Lab Med 114: 363-368, 1990.

22) Povey S, Burley MW, Attwood J, et al. Two loci for tuberous sclerosis: one on 9q34 and one on 16p13. Ann Hum Gent 58: 107-127, 1994.

23) Maruyama H, Seyama K, Sobajimaa J, et al. Multifocal micronodular pneumocyte hyperplasia and lymphangioleiomyomatosis in tuberous sclerosis with a TSC2 gene. 14: 609-614, 2001.

24) Kawashima M, Kobayashi H, Tominaga M, Yathunami J, Hayashi S. A case of micronodular pneumocyte hyperplasia, lymphangiomyomatosis associated with tuberous sclerosis. Nihon Kokyuki Gakkai Zassi 39: 277-280, 2001 (in Japanese).

25) Mc Carty KS Jr, Mossler Ja, McLelland R, Sieker HO. Pulmonary lymphangiomyomatosis responsive to progesterone. N Engl J Med 303: 1461-1465, 1980.

26) Tomasian A, Greenberg MS, Rumerman H. Tamoxifen for lymphangioleiomyomatosis (letter). New Engl J Med 396: 745-746, 1982. 